\title{
Chemo-characterization and optimization of macro and micro nutrients for exopolysaccharides and mycelia growth in pleurotus tuberregium (RUMPH, EX FR)
}

\author{
Oluwasayo Kehinde MOYIB ${ }^{1 *}$, Oluseyi Damilola ADEJOYE², Folake Ramat SODIQUE ${ }^{3}$ (D)
}

\begin{abstract}
Exoploysaccharides are potential nutraceutic, probiotic, phamarceutic and cosmesceutic natural products in fungi. Pleurotus tuberregium is an underutilized tropical fungus that is useful as food with recent reports of pharmacological activities. The present study evaluated and characterized environmental conditions and nutrients for optimal $P$. tuberregium mycelia growth (PtMG) and exopolysaccharides (PtEPS) production using batch culturing and diverse chemometric methods, respectively. Rank-sum analysis categorized the assessed conditions and nutrients into six stimulatory classes and most suitable nutrients and conditions for PtMG and PtEPS were co-identified with analysis of variance. Glucose, yeast, sodium chloride $(\mathrm{NaCl})$ and tricalcium diphosphate $\left(\mathrm{Ca}_{3}\left(\mathrm{PO}_{4}\right)_{2}\right)$ were excellent stimulant (ES) for both PtEPS and PtMG under culturing condition of pH 6 at $30{ }^{\circ} \mathrm{C}$ for $15 \mathrm{~d}$. The Chemo-phene trees generated by cluster analysis allowed visualization and clear-cut demarcation of the six stimulatory classes. The information embedded in the present study is useful for improving and developing culturing media for optimal PtMG and PtEPS yields, enabling maximal P. tuberregium utilization as food and medicine.
\end{abstract}

Keywords: chemometrics; environmental condition and nutrients; P. tuberregium exopolysaccharides (PtEPS); P. tuberregium mycelia growth (PtMG); stimulant.

Practical Application: Industrial utilization of $P$. tubberregium for production of exopolysaccharide and fungus biomass.

\section{Introduction}

Exopolysaccharides (EPS) are membrane bound polysaccharides found in large family of lower organisms including fungi and released as slime/capsules into immediate environments. Some roles ascribed to EPS in fungi are substrate adhesion, defense, adsorption and storage of nutrients (Wotton, 2004). EPS are high molecular weight polymers of diverse homo or heterosugars (Zhang et al., 2004; Zhao et al., 2014). The immunomodulatory, antimicrobials, antioxidant, antitumor, hypoglycemic and anti-tyrosinase properties of EPS have been reported (Hwang, et al., 2005; Borges et al., 2013; Barakat \& Sadik, 2014; Zhao et al., 2014). Therefore, EPS has potential applications in pharmaceutical, neutraceutical, and probiotical for many devastating diseases such as diabetes and cancer. Bae et al. (2005) reported potentials of EPS in cosmetics, cosmeceutical, and nutricosmetical industries for skin treatment. In addition, EPSs are use industrially, as emulsifiers, thickeners, stabilizers, and gelling agents (Mahapatra \& Banerjee, 2013).

Exopolysaccharides have been isolated in diverse fungi using different techniques and biomass materials and still possess similar medicinal properties (Borges et al., 2013; Zhao et al., 2014; Anike et al., 2015). Advantages of bio-exopolysaccharides over chemosynthetic EPS are: they are renewable, non-toxic and biodegradable (Freitas et al., 2011). Fungi of the Pleurotus genus are nutritious because of their reported high content of proteins, fibers, low calorie, vitamins and minerals content (Reis et al.,
2012). Their extracts in various solvents and bioactive have been tested for various pharmacological properties for therapeutic and preventive purposes and these properties are associated to their polysaccharides content (Hwang, et al., 2005; Borges et al., 2013; Barakat \& Sadik, 2014; Zhao et al., 2014).

Pleurotus tuberregium (Fr.), the king tuber mushroom, is a lesser known edible fungus that belongs to the Basidiomycotina and mainly distributed in tropical and subtropical regions such as Africa, Australia, and China with history of use as food and medicine (Oso, 1977). In Nigerian village settings, it is use mainly as a substitute for meat protein in stew and soups, and is cherish as a delicacy in many dishes as a flavor and important nutrients in urban. It can be cooked alone as mushroom soup or with other vegetables or assorted porridge dishes. Extracts from $P$. tuberregium have been associated with antitumor and superoxide radical scavenging activities and for treating headaches, fever and stomach upsets (Zhang et al., 2004; Oyetayo, 2011). Its EPS has been shown to possess pharmacological activities such as antihyperglycemic, antihyperlipidemic and antioxidant properties (Huang et al., 2012; Bamigboye et al., 2016).

Nevertheless, the potential of $P$. tuberregium to produce EPS and fungus biomass for food and medicinal uses is underexplored. In addition, few studies have been conducted to identify the best cultivation conditions and extensive nutrient 
supplements for its EPS production in submerged fermentation. Furthermore, chemometric methods such as Duncan multiple range test, rank-sum and cluster analysis for characterization and identification of most suitable culturing conditions and nutrients in fungi are underexplored. Therefore, characterization, identification using chemometrics and optimizing environmental conditions and nutrient supplements for optimal PtEPS and PtMG in submerged fermentation is sought in the present study to maximize P. tuberregium utilization for EPS and MG production.

\section{Materials and methods}

All chemical reagents were of AOAC standard and distilled water was prepared in the Department of Chemical Sciences Laboratory, Tai Solarin University of Education, Ijagun, Ijebu-Ode, Nigeria, where all experiments were carried out in batch culturing mode in three replicates.

\subsection{Microorganism sample}

Sclerotia of Pleurotus tuberregium used in this study were purchased from Bodija market, Ibadan, Oyo State, Nigeria. The sclerotia were washed thoroughly with tap water to remove adhering debris, dried at $30^{\circ} \mathrm{C}$ to constant weight and stored at room temperature $\left(25 \pm 2{ }^{\circ} \mathrm{C}\right)$. A hundred gram sclerotia was soaked in dil. $\mathrm{H}_{2} \mathrm{O}$ for $30 \mathrm{~min}$, incubated for $3 \mathrm{~d}$ and finally, plated on $4 \%$ malt extract agar medium at $25^{\circ} \mathrm{C}$.

\subsection{Assessment of environmental culturing conditions}

Basal medium ( $\mathrm{pH}$ 7.0) used contained $3 \mathrm{~g}$ yeast extract, $3 \mathrm{~g}$ malt extract, $1 \mathrm{~g}$ potassium dihydrogen phosphate hydrate $\left(\mathrm{KH}_{2} \mathrm{PO}_{4} \cdot \mathrm{H}_{2} \mathrm{O}\right), 50$ g glucose, $5 \mathrm{~g}$ calcium nitrate $\left(\mathrm{Ca}\left(\mathrm{NO}_{3}\right)_{2}\right)$, $1 \mathrm{~g}$ nicotinic acid, and $1 \mathrm{~g}$ magnesium sulphate $\left(\mathrm{MgSO}_{4}\right)$ per litre and served as positive control throughout the study. Incubating periods of 3,6, 9, 12 and $15 \mathrm{~d}$; cultivating temperatures of $20,25,30,35,40$ and $45^{\circ} \mathrm{C}$; and $\mathrm{pH} 4,5,6,7,8,9$, and 10 were assessed for optimal yield of PtEPS and PtMG.

\subsection{Assessment of nutritional supplements}

For selection of most suitable nutrients for optimal yield of PtEPS and PtMG, 50 g glucose in the positive control medium was separately substituted with $50 \mathrm{~g}$ of fructose, xylose, sucrose, lactose, dextrose, and maltose. Three grams, each of yeast and malt extract in control medium were replaced with each of $10 \mathrm{~g} / \mathrm{L}$ yeast, peptone, ammonium oxalate $\left(\left(\mathrm{NH}_{4}\right)_{2} \mathrm{C}_{2} \mathrm{O}_{4}\right)$, ammonium sulphate $\left(\left(\mathrm{NH}_{4}\right)_{2} \mathrm{SO}_{4}\right)$, ammonium nitrate $\left(\mathrm{NH}_{4} \mathrm{NO}_{3}\right)$ and ammonium chloride $\left(\mathrm{NH}_{4} \mathrm{Cl}\right)$. For minerals, $\mathrm{KH}_{2} \mathrm{PO}_{4} \cdot \mathrm{H}_{2} \mathrm{O}$ was swop with tricalcium phosphate $\left(\mathrm{Ca}_{3}\left(\mathrm{PO}_{4}\right)_{2}\right)$ and sodium dihydrogen phosphate $\left(\mathrm{NaH}_{2} \mathrm{PO}_{4}\right)$; and sulphate ion as $\mathrm{MgSO}_{4}$ was replaced with hydrates of iron (ii) sulphate $\left(\mathrm{FeSO}_{4} 7 \mathrm{H}_{2} \mathrm{O}\right)$, zinc sulphate $\left(\mathrm{ZnSO}_{4} 7 \mathrm{H}_{2} \mathrm{O}\right)$ and copper (ii) sulphate $\left(\mathrm{CuSO}_{4} \cdot 7 \mathrm{H}_{2} \mathrm{O}\right)$; and $1 \mathrm{~g}$ each of $\mathrm{Na}, \mathrm{Ca}, \mathrm{K}$ and $\mathrm{Mg}$ chloride salt was added-value. Thirty millimeters of each experimental medium was sterilized at $121^{\circ} \mathrm{C}$ for $15 \mathrm{~min}$ at $96 \mathrm{psi}$ and $0.3 \mathrm{ml}$ of $10 \%$ lactic acid was added to suppress bacterial growth after sterilization. Each $30 \mathrm{ml}$ medium was inoculated with a $12 \mathrm{~mm}$ agar plus disc of vigorously growing $P$. tuberregium mycelium.

\subsection{Determination of PtMG and total PtEPS in dry weight}

The dry weight yield of PtMG was determined by filtration of the mycelium cultured medium through No. 1. Whatman filter paper. The residue was air dried to a constant weight using a sensitive weighing balance (Baran scientific and instrument company, England). The crude PtEPS from the various cultures was isolated using precipitation method. Ten milliliters of each cultured sample were transferred into a clean test tube and centrifuged at $4500 \mathrm{rpm}$ for $15 \mathrm{~min}$ using Cole Centrifuge model 0414-1. Five milliliters of the supernatant was carefully transferred into a clean test tube with an addition of $10 \mathrm{ml} \mathrm{96 \%}$ ethanol and left overnight at $4{ }^{\circ} \mathrm{C}$. The precipitate was recovered by centrifugation at $4500 \mathrm{rpm}$ for $15 \mathrm{~min}$ and washed successfully with $96 \%$ ethanol/ $\mathrm{H}_{2} \mathrm{O}(1: 4 \mathrm{v} / \mathrm{v})$, lyophilized (Labconco Vacutec) and weighed.

\subsection{Analysis of data}

Precision measures, ANOVA, and correlation analyses were carried out using SAS v. 9.2 (Statistical Analysis System, 2002). Characterization of environmental conditions and nutrients for PtMG and PtEPS yield was by chemometrics: Duncan multiple range tests, rank-sum analysis according to Moyib et al. (2015b), and Chemo-phene trees by dissimilarity analysis representative for windows (DARwin, Perrier \& Jacquemoud-Collet, 2006).

\section{Results and discussion}

\subsection{Optimizing environmental conditions}

The pattern of trends shown in Figure 1 indicate favorable acidic medium, long incubating periods and increasing cultivating temperature till a peak at $30^{\circ} \mathrm{C}$ for high yield of PtMG and PtEPS. Medium acidity of $\mathrm{pH}$ 6, culturing temperature of $30^{\circ} \mathrm{C}$ and incubating period of $15 \mathrm{~d}$ were most suitable environmental conditions for production of both PtMG and PtEPS in P. tuberregium. Analysis of varance statistics shows various initial medium $\mathrm{pHs}$, incubating periods and cultivating temperatures were highly significant for both the PtMG and PtEPS $\left(\mathrm{p}<0.0001, \mathrm{r}^{2}=0.99\right)$ except for non-significant difference among cultivating periods of 20, 25 and $35 \mathrm{~d}$ for PtEPS and Pearson correlation analysis shows a strong inverse relationship among level of $\mathrm{pH}$ with PtMG $\left(\mathrm{p}<0.0001, \mathrm{r}^{2}=-0.82\right)$ and PtEPS $\left(\mathrm{p}<0.0001, \mathrm{r}^{2}=-0.81\right)$ yields. Therefore, as the culturing medium acidity increases, levels of PtMG and PtEPS were decreasing, supporting a favorable acidic medium for $P$. tuberregium growth and metabolic activities as noted earlier. Incubating period had positive relationships with PtMG $\left(\mathrm{p}<0.0001, \mathrm{r}^{2}=0.84\right)$ and PtEPS $\left(\mathrm{p}<0.0001, \mathrm{r}^{2}=0.81\right)$, supporting lengthy incubation period. Cultivating temperature showed inverse relationships with both PtMG $\left(\mathrm{p}<0.05, \mathrm{r}^{2}=-0.59\right)$ and PtEPS $\left(\mathrm{P}<0.001, \mathrm{r}^{2}=-0.65\right)$ and apparently, indicates higher levels of PtMG and PtEPS at low temperatures, but highest level was obtained with a median temperature $\left(30^{\circ} \mathrm{C}\right)$ and hence, the low $\mathrm{r}^{2}(0.59)$. The present results are similar to previous reports of acidic medium, a cultivating temperature above room temperature and above $10 \mathrm{~d}$ incubating period in fungi (Nehad \& El-Shamy, 2010; Adejoye, et al. 2012; Joshi et al., 2013; Lai et al., 2014). 


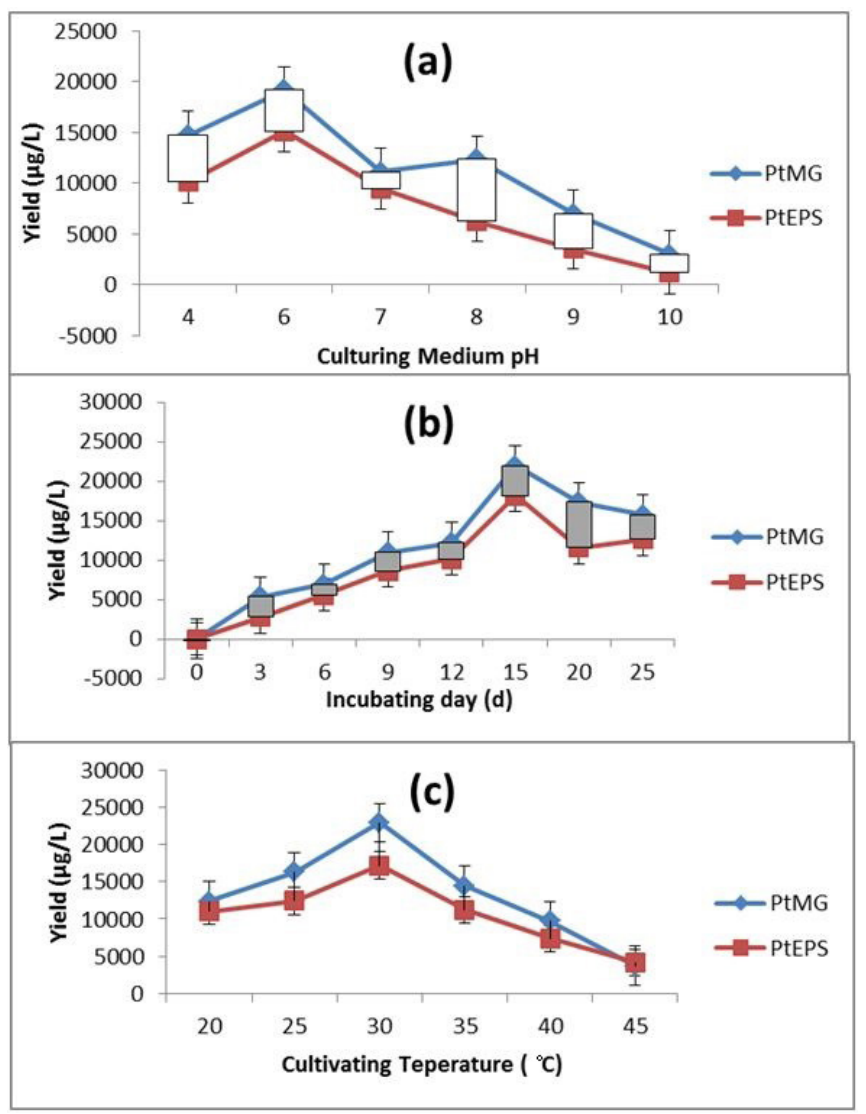

Figure 1. Trend of PtMG and PtEPS among environmental conditions in P. tuberregium. (a) Pattern of PtMG and EPS among various assessed media $\mathrm{pH}(\mathrm{b})$ pattern of PtMG and PtEPS among incubating periods (c) pattern of among cultivating temperatures.

\subsection{Identifying suitable macro and micro nutrient sources}

\section{Optimal carbon sources for energy}

Figure 2a shows glucose and lactose with highest and lowest yields, respectively, for both PtMG and PtEPS. Adejoye et al. (2012) suspicious of galactose' positive role in lactose for $L$. squarrosulus is somehow supported with its fourth position to glucose. The very low levels of PtMG and PtEPS observed in the negative control indicate $P$. tuberregium could survive in no-sugar medium but with low metabolic activities. Yields of PtMG and PtEPS were significantly distinct among the various carbon sources $(\mathrm{p}<0.0001$, $\left.\mathrm{r}^{2}=0.99\right)$. The present choice of glucose as optimal carbon source for both PtMG and PtEPS is similar to reports in fungi (Nehad \& El-Shamy, 2010; Barakat \& Sadik, 2014; Lai, et al., 2014) and contrasts to starch, sucrose, maltose and xylose in some other studied fungi (Joshi et al., 2013; Mahapatra \& Banerjee, 2013; Anike et al., 2015). Though, many diverse explanations such as affinity of a particular fungus for a specific sugar and preference between mono- and disaccharides were given but many lack biochemical elucidation. The present results are expected for glucose, one, as the only starting and direct sugar for glycolytic pathway that generates ATP in cells respiration (Berg et al., 2007). Two, the transportation barrier varies from facilitated simple diffusion for monosaccharides to active transport for maltose (Garrett \& Grisham, 2005; Berg et al., 2007). Three, enzymes

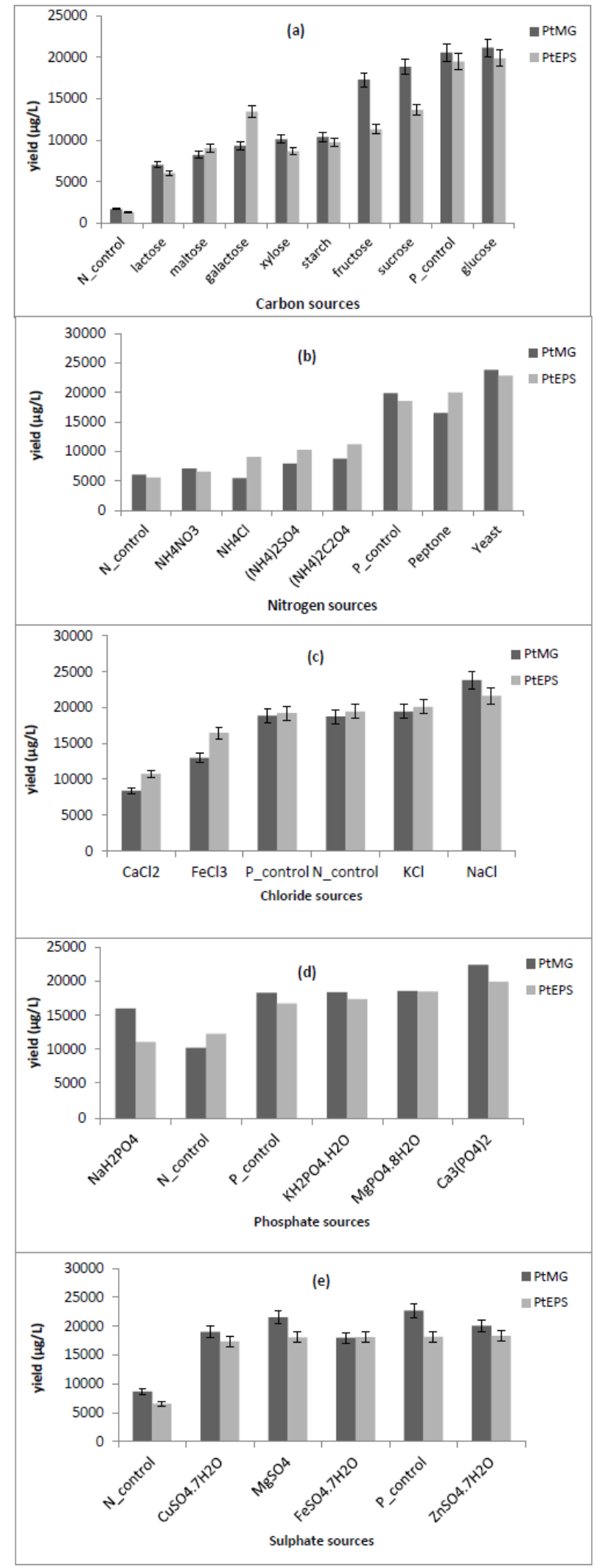

Figure 2. Trend of PtMG and PtEPS among carbon, nitrogen, and micro nutrients sources in $P$. Tuberregium, (a) carbons (b) nitrogen (c) chlorides (d) phosphates (e) sulphates. P_Control, positive control medium; N_control, basal medium without (a) glucose, (b) yeast and malt extract, (c) chloride, (d) $\mathrm{KH}_{2} \mathrm{PO}_{4}$ and (e) $\mathrm{MgSO}_{4}$. 
affinity for substrate suggests greater affinity of hexokinase to hexoses than glucosidase to disaccharides for breaking glycosidic bond (Garrett \& Grisham, 2005; Berg et al., 2007). Therefore, the present result infers rate of metabolism of sugars, perhaps, as a potential limiting factor in MG and EPS production, which requires biochemical investigation.

\section{Optimal nitrogen source for protein}

Yeast showed highest induction and closely followed by peptone for PtEPS and PtMG yields (Figure 2b). Chemo-nitrogen sources were at the bottom level indicating their lower productivity to bio-nitrogen sources in P. tuberregium. The very low levels of PtMG and PtEPS observed in negative control indicate non-absolute reliance of $P$. tuberregium on nitrogen. High significant variation was observed among the assessed nitrogen sources for both PtMG and PtEPS $\left(\mathrm{p}<0.0001, \mathrm{r}^{2}=0.99\right)$. The present result supports and establishes the importance of yeast as the most utilized nitrogen source and complex organic nitrogen are preferable over chemo-nitrogen by fungi (Nehad \& El-Shamy, 2010; Joshi et al., 2013; Mahapatra \& Banerjee, 2013; Anike et al., 2015).

\section{Optimal chloride for macromineral}

Figure $2 \mathrm{c}$ shows $\mathrm{NaCl}$ as the optimal chloride for both PtMG and PtEPS and the comparative levels obtained in the controls suggest low importance of chlorides for production of PtMG and PtEPS. The lowest level of $\mathrm{CaCl}_{2}$ suggests an inhibitory effect, which could be explained by its larger molecular size, lattice energy and the amount used in term of either micro or macro source. The present result supports $\mathrm{NaCl}$ as a choice of chloride salt for $\mathrm{MG}$ while few mentioned $\mathrm{CaCl}_{2}$ but when used as micro mineral (Lai et al., 2014; Boumaaza et al., 2015). The present result indicates low demand for chlorides as obtainable in $\mathrm{NaCl}$ while $\mathrm{CaCl}_{2}$ and $\mathrm{FeCl}_{3}$ weren't favorable and their dosage, perhaps, caused an osmotic pressure in the culturing media and might led to cytotoxicity (Turkkan, 2013).

\section{Optimal sulphate and phosphate for micronutrient}

According to Figure 2d, $\mathrm{Ca}_{3}\left(\mathrm{PO}_{4}\right)_{2}$, induced the highest level of both PtMG and PtEPS. Figure $2 \mathrm{e}$ shows $\mathrm{MgSO}_{4}$ as the optimal source for PtMG and $\mathrm{ZnSO}_{4}$ was followed by $\mathrm{FeSO}_{4} \cdot 7 \mathrm{H}_{2} \mathrm{O}$ and $\mathrm{MgSO}_{4}$ for PtEPS production. The high levels of assessed sulphates signify importance of $\mathrm{SO}_{4}{ }^{2-}$ for PtMG and PtEPS production and are in good utilizable forms (Srivastava, 1968). The assessed phosphate and sulphate salts were significantly demarcated for PtMG and PtEPS yields $\left(\mathrm{p}<0.0001, \mathrm{r}^{2}=0.99\right) . \mathrm{Ca}_{3}\left(\mathrm{PO}_{4}\right)_{2}$ as the most suitable source could replace $\mathrm{KH}_{2} \mathrm{PO}_{4}$ in culturing medium for $P$. tuberregium. Since, $\mathrm{MgSO}_{4}$ was optimal among sulphates for PtMG and followed $\mathrm{ZnSO}_{4}$ for PtEPS, $\mathrm{MgSO}_{4}$ was concluded as a choice of sulphate for both PtMG and PtEPS for convenience of further experiments. Similar studies merged phosphate and sulphate sources for assessment of optimal minerals and results reported so far differ greatly for comparison with the present observations due to non-similar mineral salts assessed (Srivastava, 1968; Turkkan, 2013; Lai et al., 2014).

\subsection{Characterization of various environmental condition and nutrients for optimal production of PtMG and PtEPS}

The 52 assessed environmental conditions and nutrients were ranked for their stimulatory effects on PtMG and PtEPS yields according to Moyib et al. (2015b). Six stimulant classes were generated, excellent stimulant (ES), good stimulant (GS), stimulant (S), fair stimulant (FS), poor stimulant (PS) and non-stimulant (NS) (Table 1). For examples, yeast, $\mathrm{NaCl}$ and $\mathrm{Ca}_{3}\left(\mathrm{PO}_{4}\right)_{2}$ were classified as ES for both PtMG and PtEPS; glucose was ES for PtEPS but GS for PtMG (detailed classification is provided in Table 1). A chemo-phene tree was generated to reveal relationships and visual groupings among the 52 environment and nutrient conditions (Figure 3). Figure 3 reveals six clusters for PtEPS and each cluster was distinct for each stimulant class in Table 1 except for few odds. Examples, for PtEPS, cluster 2 consists ES with an odd GS class (-vechloride), and cluster 4 has $S$ class with an odd ES (pH6).

Noteworthy, the odd nutrients/conditions identified by the chemo-phene tree were observed at barrier between two sequential classes in Table 1 and preferably, they should be right class in their present clusters (for example, $\mathrm{pH} 6$ should be $S$ class for PtEPS). The chemo-tree for PtMG follows similar demarcations for PtEPS but with little dissimilarity (Figure not shown). Therefore, glucose and fructose should be right placed as ES and GS, respectively. Therefore, clustering is an added value that identified misclassification of odd conditions and nutrients in rank-sum analysis and also, rank-sum analysis was able to reduce the large groupings in Duncan grouping to a manageable group size and they complement one another.

Classification of nutrients and environmental conditions for their stimulatory effects on MG and EPS is scanty in fungi.

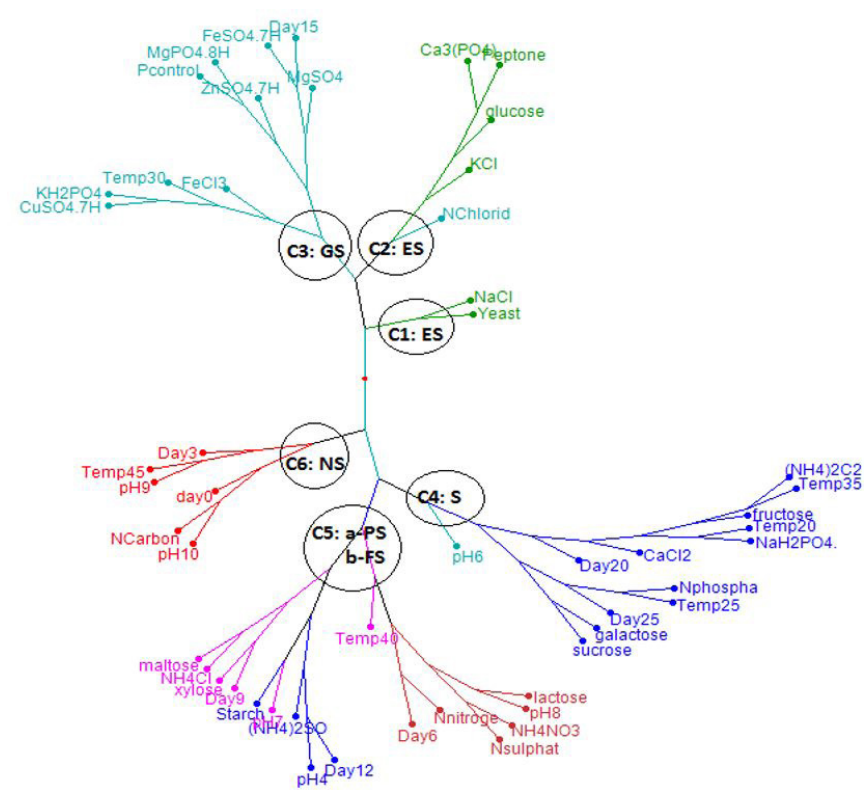

Figure 3. A chemo-phene tree for six stimulatory classes among 52 environmental conditions and nutrients for PtEPS by Cluster analysis in Darwin. Deep green = ES (Excellent stimulant), bluish-green $=$ GS (Good stimulant), blue $=\mathrm{S}$ ( (timulant), lilac $=$ FS (fair stimulant $)$, brown $=$ PS (poor stimulant), and red $=$ NS (non-stimulant). 
Table 1. Rank-sum estimates and stimulatory classes among the environmental conditions and nutrients for PtMG and PtEPS.

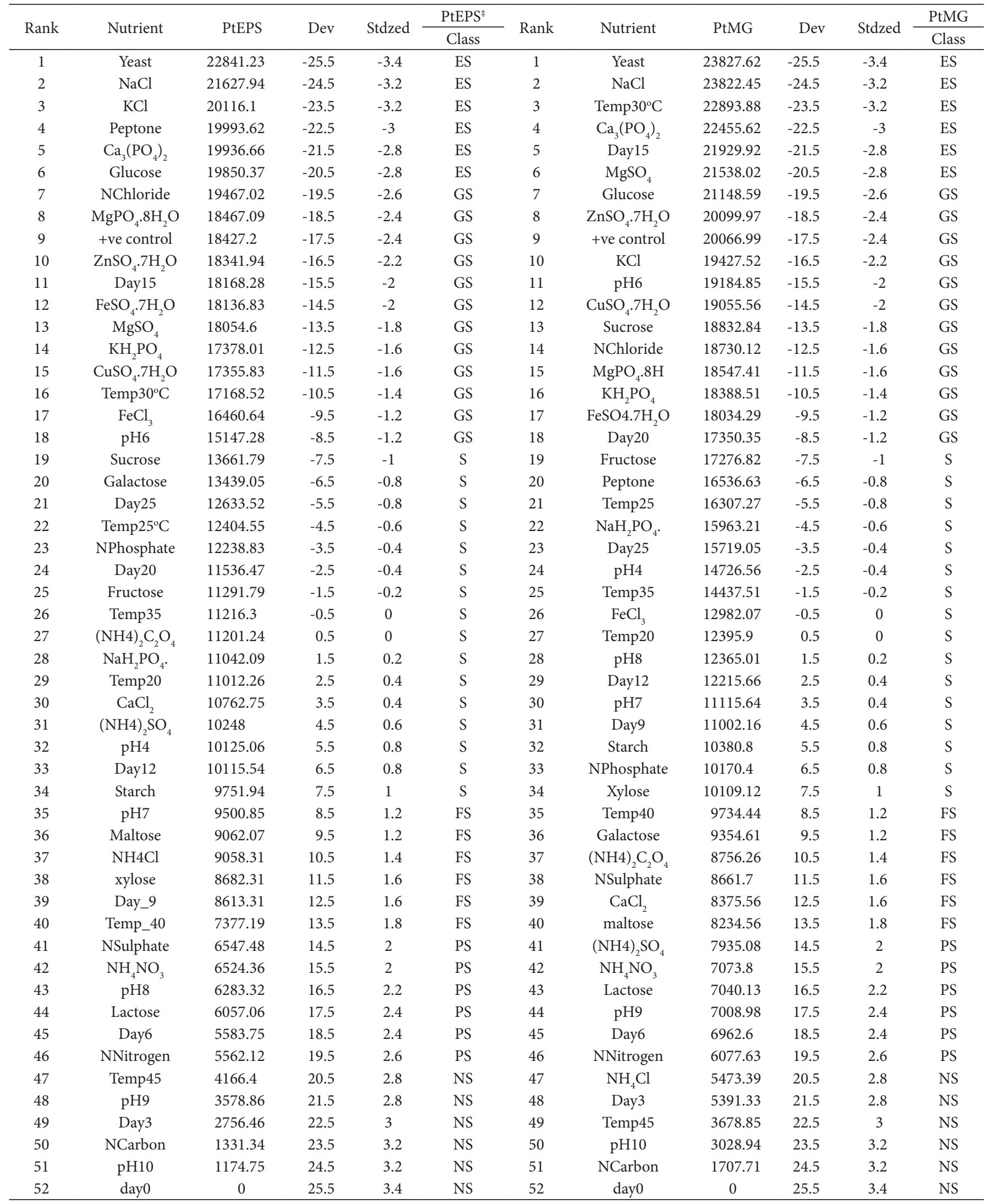

P. tuberregium exopolysaccharides (PtEPS); P. tuberregium mycelia growth (PtMG); Dev, deviation (deviation of rank from Grand mean; Stdzed, standardized mean (deviation of rank over standard deviation); NChloride, nochloride; NPhosphate, no phosphate; NSulphate, no sulphate; NNitrogen, no nitrogen; NCarbon, no carbon; ¥ES = Excellent stimulant, GS = Good stimulant, $\mathrm{S}=$ Stimulant, FS = Fair stimulant, $\mathrm{PS}=$ Poor stimulant, and NS = Non stimulant. 

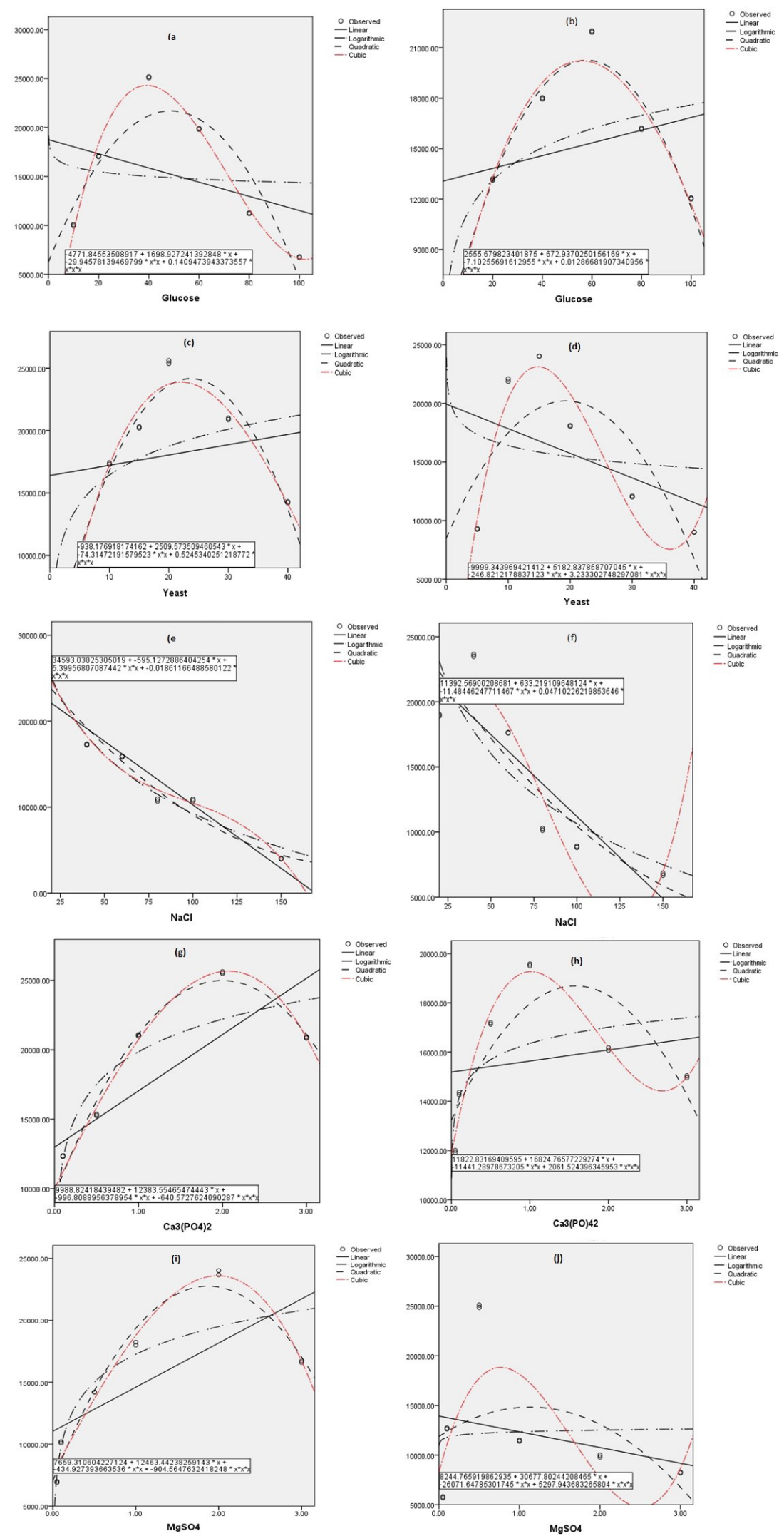

Figure 4. Optimizing glucose, yeast, $\mathrm{NaCl}$, tricalcium diphosphate, and magnesium sulphate for PtMG and PtEPS and their curve fitness (a) PtMG curve fitness for glucose, (b) PtEPS curve fitness for glucose, (c) PtMG curve fitness for yeast, (d) PtEPS curve fitness for yeast, (e) PtMG curve fitness for $\mathrm{NaCl}$, (f) PtEPS curve fitness for $\mathrm{NaCl}$, (g) PtMG curve fitness for $\mathrm{Ca}_{3}\left(\mathrm{PO}_{4}\right)_{2}$, (h) PtEPS curve fitness for $\mathrm{Ca}_{3}\left(\mathrm{PO}_{4}\right)_{2}$, (i) PtMG curve fitness forMgSO ${ }_{4}$, and (j) PtEPS curve fitness for $\mathrm{MgSO}_{4}$. P. tuberregium exopolysaccharides (PtEPS); P. tuberregium mycelia growth (PtMG); the white area in the curve is the corrected equation for the best fitted cubic model curve depicted in red color in the grey area. 
However, such classification has been reported for proper utilization in food crops (Moyib et al., 2015a, 2015b) and at present extended to $P$. tuberregium. Nonetheless, selection of optimal conditions and nutrients based on ANOVA, response surface methodology, orthogonal matrix method, and Plackett-Burman design, for optimization of EPS production have been successful used in fungi (Borges et al., 2013; Joshi et al., 2013; Mahapatra \& Banerjee, 2013) and the present chemometrics, Duncan multiple range test, rank-sum procedure and clustering analysis are also suffice, robust, simple, informative and self- explanatory in nature.

\subsection{Optimization of dosages of glucose, yeast, $\mathrm{NaCl}, \mathrm{MgSO}_{4}$ and $\mathrm{Ca}_{3}\left(\mathrm{PO}_{4}\right)_{2}$}

Figure $4 \mathrm{a}$ and $\mathrm{b}$ show increasing glucose level from 10 to $100 \mathrm{~g} / \mathrm{L}$ in a culture medium containing $10 \mathrm{~g}$ yeast, $1.0 \mathrm{~g}$ nicotinic acid, $20 \mathrm{~g} \mathrm{NaCl}, 1 \mathrm{~g} \mathrm{MgSO}_{4}$ and $1 \mathrm{~g} \mathrm{Ca}_{3}\left(\mathrm{PO}_{4}\right)_{2}$ per liter caused an increasing in the production of PtMG till $40 \mathrm{~g} / \mathrm{L}$ glucose and PtEPS production increases till $60 \mathrm{~g} / \mathrm{L}$ glucose, after which both fell gradually till $100 \mathrm{~g} / \mathrm{L}$ glucose. Glucose has been reported in varying amounts that ranged between 40 and $100 \mathrm{~g} / \mathrm{L}$ for optimal production of EPS, of which the present selected concentrations of 40 (PtMG) and $60 \mathrm{~g} / \mathrm{L}$ (PtEPS) are within the range reported for many fungi. Such high demand of glucose for EPS has been previously observed, even at higher $\mathrm{NaCl}$ levels (Nehad \& El-Shamy, 2010; Lai et al., 2014). The higher glucose required for PtEPS over PtMG should be expected, since glucose is one of the basic units of EPS as glucans and mannogalactans (Zhang et al., 2004; Huang et al., 2012).

For yeast, 5 to $40 \mathrm{~g} / \mathrm{L}$ dosages were evaluated, PtEPS and PtMG responded positively to increasing the dosage of yeast till $15 \mathrm{~g} / \mathrm{L}$ and $20 \mathrm{~g} / \mathrm{L}$, respectively, after which, both fell gradually with increasing yeast dose till $40 \mathrm{~g} / \mathrm{L}$ (Figure $4 \mathrm{c}$, d). Therefore, in the presence of $50 \mathrm{~g}$ glucose and $20 \mathrm{~g} \mathrm{NaCl}$, a moderate dose of $15 \mathrm{~g} / \mathrm{L}$ and $20 \mathrm{~g} / \mathrm{L}$ yeast favored PtEPS and PtMG production, respectively and are comparable to $25 \mathrm{~g} / \mathrm{L}$ chosen for MG and EPS, in L. squarrosulus (Anike et al., 2015) while lower concentrations of yeast have been reported in some other fungi (Nehad \& El-Shamy, 2010; Joshi et al., 2013).

Concentrations of $\mathrm{NaCl}$ for optimization was tested from 20 to $150 \mathrm{~g} / \mathrm{L}$ in a medium containing $50 \mathrm{~g}$ glucose, $20 \mathrm{~g}$ yeast, $1 \mathrm{~g}$ each of $\mathrm{Ca}_{3}\left(\mathrm{PO}_{4}\right), \mathrm{MgSO}_{4}$ and nicotinic acid. Figure 4 e shows increasing $\mathrm{NaCl}$ dose beyond $20 \mathrm{~g} / \mathrm{L}$ reduced PtMG production, and growth was halted at $100 \mathrm{~g} / \mathrm{L}$, indicating salt saturation with a low yield at highest dose of $150 \mathrm{~g} / \mathrm{L}$. PtEPS production was favorable till $40 \mathrm{~g} / \mathrm{L} \mathrm{NaCl}$ and depreciated with further increasing dose (Figure 4f). The present result suggests $\mathrm{NaCl}$ is a value-added nutrient but at moderate concentration that shouldn't exceed $40 \mathrm{~g} / \mathrm{L}$, beyond which the growth of $P$. tuberregium could be stunted and PtEPS production truncated (Turkkan, 2013; Boumaaza et al., 2015).

Surprisingly, level of PtEPS increases gradually with increasing dose of $\mathrm{PO}_{4}^{3-}$ from $0.05 \mathrm{~g}$ to $1.00 \mathrm{~g} / \mathrm{L}$ and reduces sharply at increasing dose beyond $1.0 \mathrm{~g} / \mathrm{L}$ while PtMG increases sharply till a dose of $2 \mathrm{~g} / \mathrm{L}$ and fell at $3 \mathrm{~g} / \mathrm{L}$ (Figure $4 \mathrm{~g}$, h). The result shows that $\mathrm{PO}_{4}^{3-}$ supported production of both PtEPS and PtMG but at different doses. Production of PtMG increases with increasing dose of $\mathrm{MgSO}_{4}$ till $2 \mathrm{~g} / \mathrm{L}$ and fell sharply at $3 \mathrm{~g} / \mathrm{L}$ (Figure $4 \mathrm{i}, \mathrm{j}$ ). PtEPS showed a different pattern, it increases with increasing dose till $0.5 \mathrm{~g}$ and dropped sharply at $1.0 \mathrm{~g}$ and then gradually till $3 \mathrm{~g} / \mathrm{L}$, indicating higher requirement of sulphate for PtMG than PtEPS. The present results signifies $\mathrm{Ca}_{3}\left(\mathrm{PO}_{4}\right)_{2}$ and $\mathrm{MgSO}_{4}$ are important nutrients require in minute quantity as expected of microminerals and are within the reported range in fungi (Mahapatra \& Banerjee, 2013; Lai et al., 2014). Generally, the patterns of the curves generated for PtMG and PtEPS production using regression analytical tool in SPSS (v. 17) were best fitted with cubic model.

\section{Conclusions}

The present chemometrics, Duncan multiple range test, ranksum analysis and hierarchical clustering in the given successive sequential order, complement one another, and were able to classify assessed conditional and nutrient sources into useful stimulatory classes for optimal yields of PtEPS and PtMG and allowed robust selection of most suitable nutrients for PtEPS and PtMG. The present results are useful for production of PtMG and PtEPS for pharmaceutical, food, cosmetics and any applicable industrial purposes.

\section{References}

Adejoye, O. D., Moyib, O. K., \& Eso, A. O. (2012). Production of exopolysaccharide and fungus biomass by a Nigeria edible mushroom (Lentinus squarrosulus) under varying submerged culture conditions. AFS, 34(2), 111-117.

Anike, F. N., Isikhuemhen, O. S., Blum, D., \& Neda, H. (2015). Nutrient Requirements and Fermentation Conditions for Mycelia and Crude Exo-Polysaccharides Production by Lentinus squarrosulus. Advances in Bioscience and Biotechnology, 6(8), 526-536. http:// dx.doi.org/10.4236/abb.2015.68055.

Bae, J. T., Sim, G. S., Lee, D. H., Lee, B. C., Pyo, H. B., Choe, T. B., \& Yun, J. W. (2005). Production of exopolysaccharide from mycelial culture of Grifola frondosa and its inhibitory effect on matrix metalloproteinase-1 expression in UV-irradiated human dermal fibroblasts. FEMS Microbiology Letters, 251(2), 347-354. http:// dx.doi.org/10.1016/j.femsle.2005.08.021. PMid:16165320.

Bamigboye, C. O., Oloke, J. K., \& Dames, J. F. (2016). Biological activity of extracellular and intracellular polysaccharides from Pleurotus tuber-regium: Hybrid and mutant Strains. Journal of Food and Nutrition Research, 4(7), 422-428.

Barakat, O. S., \& Sadik, M. W. (2014). Mycelial growth and bioactive substance production of pleurotusostreatusin submerged culture. International Journal of Current Microbiology and Applied Sciences, 3(4), 1073-1085.

Berg, J. M., Tymoczko, J. L., \& Stryer, L. (2007). Biochemistry (6th ed.). New York: Freeman.

Borges, G. M., Barba, F. F., Schiebelbein, A. P., Pereira, B. P., Chaves, M. B., Silveira, M. L., Pinho, M. S., Furlan, S. A., \& Wisbeck, E. (2013). Extracellular polysaccharide production by a strain of Pleurotus djamor isolated in the south of Brazil and antitumor activity on Sarcoma 180. Brazilian Journal of Microbiology, 44(4), 1059-1065. http:// dx.doi.org/10.1590/S1517-83822014005000019. PMid:24688493.

Boumaaza, B., Benkhelifa, M., \& Belkhoudja, M. (2015). Effect of two salts compounds on mycelia growth, sporulation and spore germination of six isolates of Botrytis cinerea in the Western North 
of Nigeria. International Journal of Microbiology, 2015(1), 572626. http://dx.doi.org/10.1155/2015/572626. PMid:25883657.

Freitas, F., Alves, V. D., \& Reis, M. A. (2011). Advances in bacterial exopolysaccharides: from production to biotechnological applications. Trends in Biotechnology, 29(8), 388-398. http://dx.doi.org/10.1016/j. tibtech.2011.03.008. PMid:21561675.

Garrett, R., \& Grisham, C. M. (2005). Biochemistry (3th ed.). Belmont: Thomson Brooks/Cole.

Huang, H. Y., Korivi, M., Chaing, Y. Y., Chien, T. Y., \& Tsai, Y. C. (2012). Pleurotus tuber-regium polysaccharides attenuate hyperglycemia and oxidative stress in experimental diabetic rats. Evidence-Based Complementary and Alternative Medicine, 2012(1), 856381. http:// dx.doi.org/10.1155/2012/856381. PMid:22973406.

Hwang, H. J., Kim, S. W., Lim, J. M., Joo, J. H., Kim, H. O., Kim, H. M., \& Yun, J. W. (2005). Hypoglycemic effect of crude exopolysaccharides produced by a medicinal mushroom, Phellinus baumii in streptozotocininduced diabetic rats. Life Sciences, 76(26), 3069-3080. http://dx.doi. org/10.1016/j.lfs.2004.12.019. PMid:15850599.

Joshi, M., Patel, H., Gupte, S., \& Gupte, A. (2013). Nutrient improvement for simultaneous production of exopolysaccharide and mycelial biomass by submerged cultivation of Schizophyllum commune AGMJ-1 using statistical optimization. 3 Biotech, 3(4), 307-318. https://doi. org/10.1007/s13205-012-0103-3. PMid:28324588.

Lai, W. G., Sulleh, S. M., David, F., Zainel, Z., Othman, A. M., \& Suleh, N. M. (2014). Optimization of submerged culture conditions from the production of mycelia biomass and exopolysaccharide from Lignosus rhinocerus. Sains Malaysiana, 43(1), 73-80.

Mahapatra, S., \& Banerjee, D. (2013). Fungal exopolysaccharide: production, composition and applications. Microbiology Insights, 6, 1-16. http://dx.doi.org/10.4137/MBI.S10957. PMid:24826070.

Moyib, O. K., Alashiri, G. O., \& Adejoye, O. D. (2015a). Chemometric dissimilarity in nutritive value of popularly consumed Nigerian brown and white common beans. Food Chemistry, 166, 576-584. http://dx.doi.org/10.1016/j.foodchem.2014.06.069. PMid:25053096.

Moyib, O. K., Mkumbira, J., Odunola, A. O., Dixon, A. G. O., Akoroda, M. O., \& Kulakow, P. (2015b). Genetic variation of postharvest physiological deterioration susceptibility in a cassava germplasm. Crop Science, 55(6), 2701-2711. http://dx.doi.org/10.2135/cropsci2014.11.0749.
Nehad, E. A., \& El-Shamy, A. R. (2010). Physiological studies in the production of exopolysaccharide by fungi. Agriculture and Biology Journal of North America, 1(6), 1303-1308. http://dx.doi.org/10.5251/ abjna.2010.1.6.1303.1308.

Oso, B. A. (1977). Pleurotus tuber-regium from Nigeria. Mycologia, 69(2), 271-279. http://dx.doi.org/10.1080/00275514.1977.120200 58. PMid:559245.

Oyetayo, O. V. (2011). Medicinal uses of mushrooms in Nigeria: towards full and sustainable exploitation. African Journal of Traditional, Complementary, and Alternative Medicines, 8(3), 267-274. http:// dx.doi.org/10.4314/ajtcam.v8i3.65289. PMid:22468005.

Perrier, X., \& Jacquemoud-Collet, J. P. (2006). DARwin software. Retrieved from http://darwin.cirad.fr/darwin

Reis, F. S., Barros, L., Martins, A., \& Ferreira, I. C. F. R. (2012). Chemical composition and nutritional value of the most widely appreciated cultivated mushrooms: an interspecies comparative study. Food and Chemical Toxicology, 50(2), 191-197. http://dx.doi.org/10.1016/j. fct.2011.10.056. PMid:22056333.

Srivastava, K. C. (1968). Sulphur requirements Hendersonula Toruloidea Nattrabs. Defence Science Journal, 18, 205-208.

Statistical Analysis System - SAS. (2002). Statistical analysis system. Version 9.2. Cary: SAS Institute Incorporation.

Turkkan, M. (2013). Antifungal effect of various salts against Fusarium oxysporum f. Sp. Cepae, the causal agent of Fusarium basal rot of onion. The Journal of Agricultural Science, 19, 178-187.

Wotton, R. S. (2004). The ubiquity and many roles of exopolymers (EPS) in aquatic systems. Scientia Marina, 68(S1), 13-21. http:// dx.doi.org/10.3989/scimar.2004.68s113.

Zhang, M., Zhang, L., Cheung, P. C. K., \& Ooi, V. E. C. (2004). Molecular weight and anti-tumor activity of the water-soluble polysaccharides isolated by hot water and ultrasonic treatment from the sclerotia and mycelia of Pleurotus tuber-regium. Carbohydrate Polymers, 56(2), 123-128. http://dx.doi.org/10.1016/j.carbpol.2004.01.005.

Zhao, W., Wang, X.-H., Li, H. M., Wang, S. H., Chen, T., Yuan, Z. P., \& Tang, Y. J. (2014). Isolation and characterization of polysaccharides with the antitumor activity from Tuber fruiting bodies and fermentation system. Applied Microbiology and Biotechnology, 98(5), 1991-2002. http://dx.doi.org/10.1007/s00253-013-5379-7. PMid:24272369. 